\title{
DIVERSITY AND COMMUNITY STRUCTURE OF FUNGI IN THE ROOTS OF MACHILUS PAUHOI IN DIFFERENT AGE GROUPS
}

\author{
GuO, X. F., ${ }^{1,2}$ \\ ${ }^{1}$ College of Environmental Science and Engineering, China West Normal University \\ Nanchong 637009, China \\ ${ }^{2}$ Institute of Environmental Science, China West Normal University, Nanchong 637000, China \\ (e-mail: gxfcwnu@qq.com; phone: +86-177-7838-2606) \\ (Received $7^{\text {th }}$ Nov 2018; accepted $11^{\text {th }}$ Jan 2019)
}

\begin{abstract}
In this study, in order to investigate the diversity of fungi in the roots of Machilus pauhoi in different age, we investigated the fungi diversity and community structure in the roots of Machilus pauhoi in the age of 2-year-old, 5-year-old, 8-year-old and 20-year-old by Illumina Hiseq sequencing platform. 424 fungi operational taxonomic units (OTU) were obtained. There was no significant difference in fungi abundance and diversity index between the age of 2-year-old, 5-year-old and 20-year-old, but they were higher than those in the age of 8-year-old. On phylum level, Ascomycota, Basidiomycota and Glomeromycota were the dominant species with a relative abundance of more than $1 \%$. Besides, with the increase of age, the fungi community in the roots of Machilus pauhoi showed a certain degree of change while then decreased to the equivalent level in the young age. On genus level, Clitocybula, Chaetosphaeria, Phylchara and Ochroconis were the dominant species, accounting for more than $10 \%$ of the investigated species. The specific species of Phyllachora appeared in the highest proportion in 8-yearold roots. Abundance heat map analysis showed that the fungi communities in the 2-year-old and 20-yearold roots were clustered into one category and those in the 5-year-old and 8-year-old were classified as another group. These results indicated that the fungi community in the roots of Machilus pauhoi was greatly affected by the growth age.
\end{abstract}

Keywords: endophytic fungi, high throughput sequencing, relative abundance, Venn diagram, phylogenetic tree analysis

\section{Introduction}

Soil microbes are the basis for the recycling and utilization of materials in ecosystems and are also a guarantee for the stability and normal functions of ecosystems (Chapin et al., 1997). Soil, as a site for soil microbial activity, has an important impact on microbial community and activity (Jeanbille et al., 2016; Kuramae et al., 2011). Fungi in soils play a huge role in improving the plant stress resistance and maintaining normal plant growth (Mukerji et al., 1996; Smith et al., 1999). Endophytic fungi in roots mainly results from soil microorganisms infection when contacting with soil. Soil fungi are closely related to plant growth and can affect the health and productivity of plants. As an important part of the whole plant, the endophytic fungi play a very important role in plant growth, development, accumulation of secondary metabolites and adaptation to the environment (Vandenkoornhuyse et al., 2015). Some species can enhance the resistance and daptability of the host (Kaushik et al., 2013; Iranshahi et al., 2016; Zhao et al., 2013; Kumar et al., 2013) and promote the uptake of nitrogen, phosphorus and other elements (Rodrigue et al., 2004; Azevedo et al., 2000). Some have no significant effect on plants, neither attacking plants nor promoting plant growth (Rout, 2014). And some are latent in plant tissues and remain dormant. When plants suffer from physiological and biochemical dysfunction caused by changes in the external environment, they become active to attack plants (Petrini, 1991). Endophytic fungi are 
ubiquitous in a variety of plants. However, in over ten thousand kinds of plants on the earth, only hundreds of endophytic fungi have been studied (Stone et al., 2000). In addition, the distribution of endophytic fungi in the host is often affected by various factors such as the forest age, season, altitude, and sampling number (Schmit et al., 2004).

Machilus pauhoi belongs to Lauraceae, Machilus Nees, which is a large evergreen tree with rapid growth and adaptability. It is a national second-class protected plant with high economic value in both wood and seeds (Guo et al., 2017). Because of its important ecological and economical value, Machilus pauhoi has been listed as a key tree species by Guangxi Forestry Department. It is worthy of vigorous promotion in depth (Wei et al., 2011). At present, there are few studies on Machilus pauhoi at home and abroad, and most of articles only briefly describe the cultivation techniques, ecological characteristics and basic measures for afforestation (Zhong et al., 2009). However, the effects of growth age on the diversity and community of fungi in the roots of Machilus pauhoi have not been reported. In addition, through field investigations, after 5 to 6 years of growth, yellow, brown to black irregular shape lesions appear in large areas of leaves, stems and other parts above ground, and sometimes the whole leaves are even covered by black spots, which form a black-colored convex stroma, seriously inhibiting the photosynthesis of the plant. As a result, a significant part of the plant would die, greatly reducing the survival rate of the Machilus pauhoi. Whether this phenomenon is related to some pathogens in the roots of the Machilus pauhoi is worth exploring.

At present, many researchers at home and abroad are committed to the restoration and reconstruction of fragile or degraded ecosystems, and plantations have become a better means of repair (Rappaport et al., 2014). It is necessary to restore the plants on the ground and the functional microorganisms underground that are symbiotic with plants. Given to the universal distribution of endophytic fungi in terrestrial ecosystems, the diversity of ecological functions and their important roles in the restoration and reconstruction of degraded ecosystems, and taking into account the development potential and economic value of Machilus pauhoi, this research studied the cultivated Machilus pauhoi in different age groups in Yangshan County, Qingyuan City, Guangdong Province, China for the first time. The high-throughput sequencing technology was used to reveal the diversity of fungi in the roots of Machilus pauhoi in different developmental stages. This study helped to screen the mycorrhizal fungi which could promote the growth of Machilus pauhoi. Besides, it can effectively guide the introduction and cultivation application of Machilus pauhoi. At the same time, it is necessary to explore whether the scabs formed in Machilus pauhoi are related to certain pathogens. The results of this study not only help to understand the role and status of soil microbes in the different growth years of Machilus pauhoi, but also provide a theoretical basis for the sustainable management of Machilus pauhoi.

\section{Materials and methods}

\section{Overview of the study area}

The plantation forest of Machilus pauhoi is located in Yangshan County, Qingyuan City, Guangdong Province, China (N242ㅇ', E112 ${ }^{\circ} 36^{\prime}$ ), which belongs to the monsoon climate zone with transition from south subtropical to mid-subtropical. The annual 
average temperature is $20.3{ }^{\circ} \mathrm{C}$, and the average annual rainfall is about $1850 \mathrm{~mm}$. The altitude is in the range of 10 to $270 \mathrm{~m}$, and the soil type is mainly red soil.

The original study area is mainly mountain rain forest. However, it has been damaged by human activities for a long time, resulting in secondary forests and extremely irregular physiognomy. Since 1995, the artificial test plantation of Machilus pauhoi has been constructed with similar site conditions. At present, there are four different developmental stages of Machilus pauhoi plantation with forest ages of 2 years, 5 years, 8 years and 20 years respectively. The site conditions of the plots of the test plantation were basically the same, and the row spacing was $3 \times 3 \mathrm{~m}$. A map indicating the location of sampling site was given (see Fig. 1, which was generated by Google earth). Some photos about the habitat of experimental sites are also given in Figure 2.

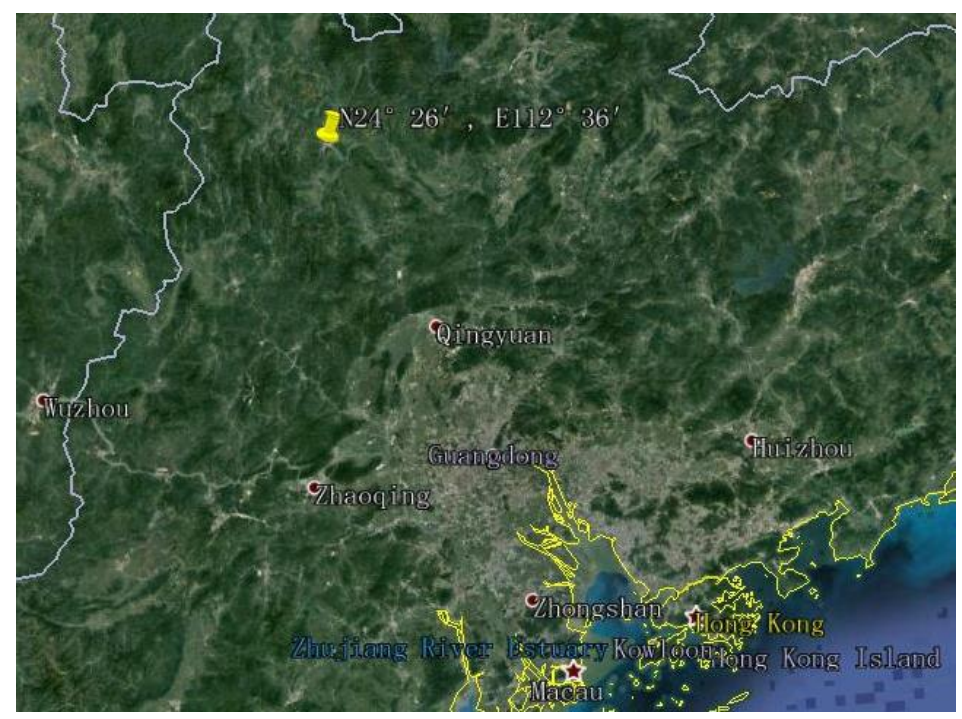

Figure 1. GPS coordinates of the sampling site

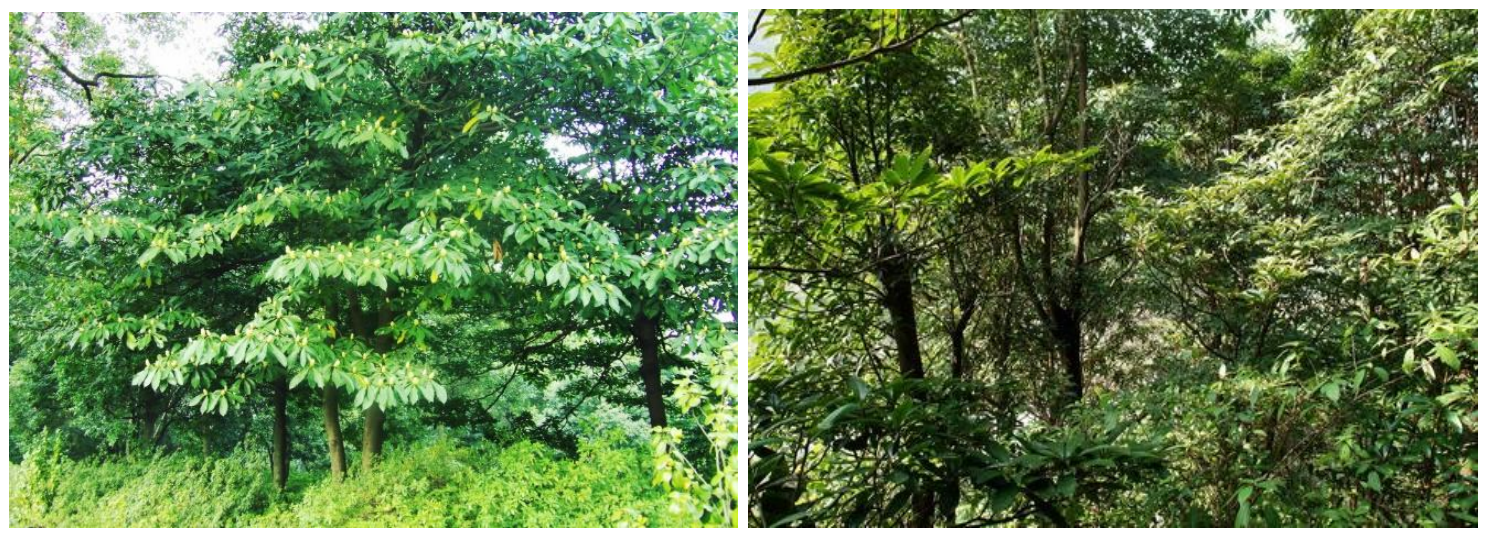

Figure 2. Habitat of the experimental sites

\section{Sampling method}

In October 2017, root samples at 4 different stages of development, i.e., 2a, 5a, 8a and 20a, were selected as the research objects from the test plantation. In order to 
reduce the error, each sample was selected in random and three parallel samples were selected. The samples of the 2a Machilus pauhoi were numbered as 2YR.1, 2YR.2, 2YR.3, and the 5a Machilus pauhoi were numbered as 5YR.1, 5YR.2, 5YR.3, 8a Machilus pauhoi were numbered as 8YR.1, 8YR.2, 8YR.3, and the 20a Machilus pauhoi were numbered as 20YR.1, 20YR.2, and 20YR.3, respectively. When selecting samples, the end part of taproots with low lignification degree were collected. Root samples were cut into $2-3 \mathrm{~cm}$ long segments first, then rinsed with tap water, then rinsed with distilled water, then soaked in 0.1\% mercury bichloride for 5-10 min, then rinsed with distilled water, then soaked in $75 \%$ alcohol for about $20 \mathrm{~s}$, then rinsed with distilled water, then dried with silica gel in aseptic self-sealing bags and marked, and then stored in a refrigerator at $4{ }^{\circ} \mathrm{C}$. A total of 12 Machilus pauhoi samples were collected.

\section{High-throughput sequencing methods}

In this study, high-throughput sequencing technology was used. DNA samples were extracted from root samples with the kit (Plant Genomic DNA Kit, Tiangen, China) using the modified Cetyl Trimethyl Ammonium Ammonium Bromide (CTAB) method (Guo et al., 2000). The concentration and purity of the extracted DNA were measured by spectrophotometer (Thermoelectric Corporation, USA). The integrity of the DNA sample was measured by $0.8 \%$ agarose gel electrophoresis at a voltage of $120 \mathrm{~V}$ and an electrophoresis time of about 20 mins.

$30 \mu \mathrm{L}$ PCR reaction system: $15 \mu \mathrm{L}$ of Phusion Master Mix $(2 \times), 3 \mu \mathrm{L}$ of Primer $(2 \mu \mathrm{mol} / \mathrm{L}), 10 \mu \mathrm{L}$ of gDNA $(1 \mathrm{ng} / \mu \mathrm{L})$, and $2 \mu \mathrm{L}$ of $\mathrm{H}_{2} \mathrm{O}$. The amplification procedure: pre-denaturation at $98^{\circ} \mathrm{C}$ for $1 \mathrm{~min} ; 30$ cycles including denaturation at $98{ }^{\circ} \mathrm{C}$ for $10 \mathrm{~s}$; annealing at $50{ }^{\circ} \mathrm{C}$ for $30 \mathrm{~s}$; extension at $72{ }^{\circ} \mathrm{C}$ for $30 \mathrm{~s}$; and extension at $72{ }^{\circ} \mathrm{C}$ for 5 min. Library preparation, homogenization, detection, computer sequencing and data quality control were all completed by Guangzhou Meg Biotechnology Co., Ltd.

The phylum and genus level was identified based on the alignments of majorizing sequence and reference sequence in the database. The uclust del method (Caron et al., 2009) was used to cluster OTUs with high-quality sequences with a similarity $\geq 97 \%$. According to the results of cluster analysis, alpha diversity analysis was carried out. The Observed species index and the Chao1 index reflect the richness of the community in the sample, that is, simply refer to the number of species in the community (the number of OTUs); the Shannon index and the Simpson index reflect the diversity of the community, and are affected by species richness and species uniformity in the sample community. The results were processed and bioinformatics analysis was carried out using Microsoft Excel 2013 and R 3.4.2 software (Knezevic et al., 2007).

\section{Results and analysis}

\section{Sequencing depth evaluation}

12 fungi samples were sequenced and a total of 557,906 sequences were obtained after sequence optimization. The sequences were randomly selected. Curves of the number of selected sequences versus the number of OTUs they represent were drawn. The OTU was clustered at 97\% similarity level and the rarefaction curves of each sample was prepared (Fig. 3). The curves gradually flatten indicating a reasonable number of sequencing. 


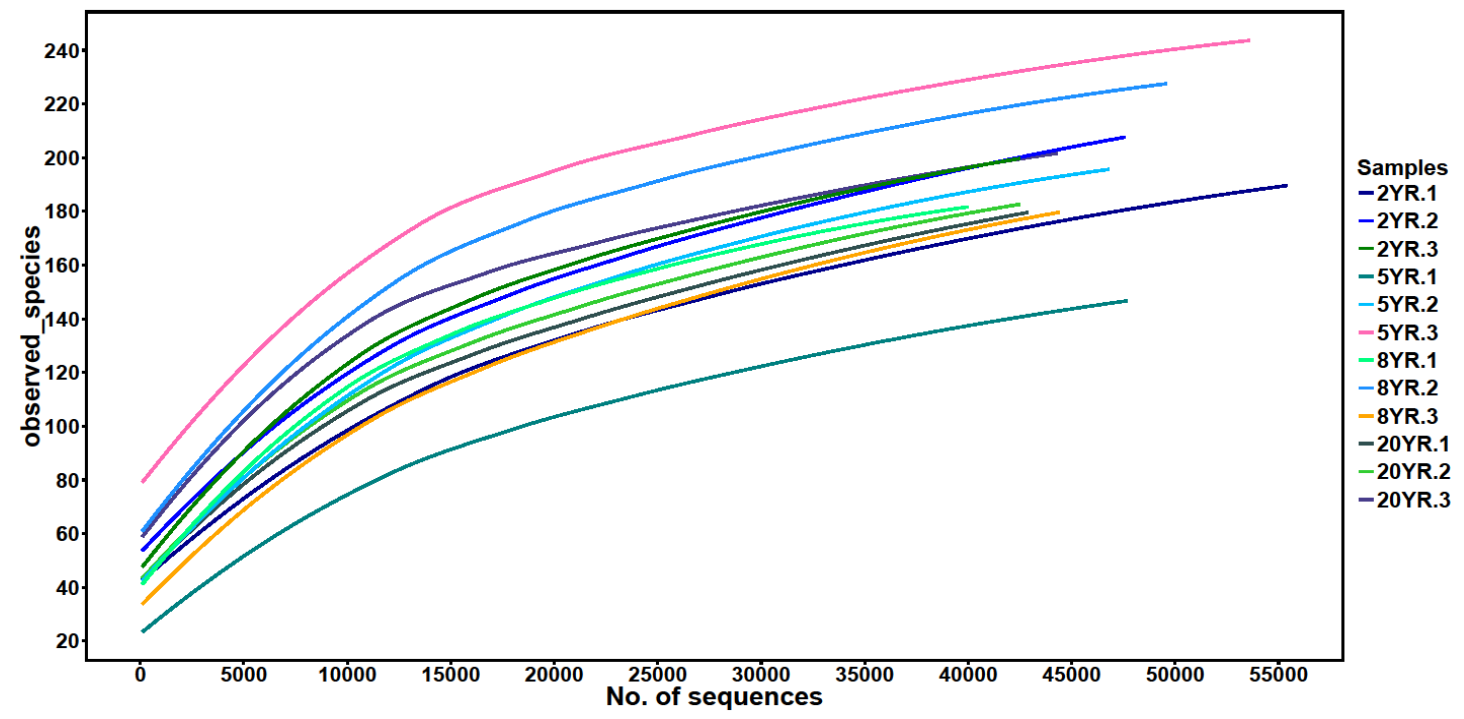

Figure 3. Rarefaction curves of roots of Machilus pauhoi

\section{Fungi diversity and OTUs in roots of Machilus pauhoi in different age groups}

It can be seen from Table 1 that the fungi richness and diversity index in the roots of 8a Machilus pauhoi are significantly lower than the other three ages. However, there is no significant difference in the abundance and diversity index of fungi communities in the roots of the 2a, 5a and 20a Machilus pauhoi.

Table 1. Diversity indexes of fungi in roots of Machilus pauhoi in different age groups

\begin{tabular}{c|c|c|c|c}
\hline Treatment & Observed species index & Chao1 index & Shannon index & Simpson index \\
\hline $2 \mathrm{a}$ & $183.67 \pm 11.72 \mathrm{a}$ & $270.9 \pm 14.11 \mathrm{a}$ & $3.16 \pm 0.04 \mathrm{a}$ & $0.78 \pm 0.04 \mathrm{a}$ \\
$5 \mathrm{a}$ & $187.00 \pm 15.59 \mathrm{a}$ & $269.02 \pm 31.96 \mathrm{a}$ & $3.17 \pm 0.3 \mathrm{a}$ & $0.77 \pm 0.09 \mathrm{a}$ \\
$8 \mathrm{a}$ & $165.33 \pm 16.06 \mathrm{~b}$ & $223.32 \pm 19.3 \mathrm{~b}$ & $2.11 \pm 1.91 \mathrm{~b}$ & $0.40 \pm 0.38 \mathrm{~b}$ \\
$20 \mathrm{a}$ & $190.33 \pm 22.68 \mathrm{a}$ & $251.65 \pm 24.47 \mathrm{a}$ & $3.31 \pm 0.58 \mathrm{a}$ & $0.82 \pm 0.05 \mathrm{a}$ \\
\hline
\end{tabular}

According to the Venn diagram (Fig. 4), which represents the relationship between the number of OTUs in the roots of Machilus pauhoi in different age, 424 fungi OTUs were obtained from all samples in 4 age groups, including 223 in the second year, 233 in fifth year, 216 in eighth year and 220 in twentieth year. The unique OTUs in the roots of 2a, 5a, 8a and 20a Machilus pauhoi are: 53, 47, 50 and 51, accounting for $12.50 \%$, $11.08 \%, 11.79 \%$ and $12.03 \%$ of the total OTU, respectively. There are 106 OTUs shared by samples in different age groups, accounting for $25.0 \%$ of the total number of OTUs. The common OTU in the roots of Machilus pauhoi in fifth year and eighth year is the most, up to 151. And the common OTUs in the roots of Machilus pauhoi in second year and twentieth year is the least as 135. The common OTUs shared by other age groups are: 141 OTUs for the second and fifth year, 143 OTUs for the second and eighth year, 147 OTUs for the twentieth and fifth year, and 135 OTUs for the twentieth and eighth year. 


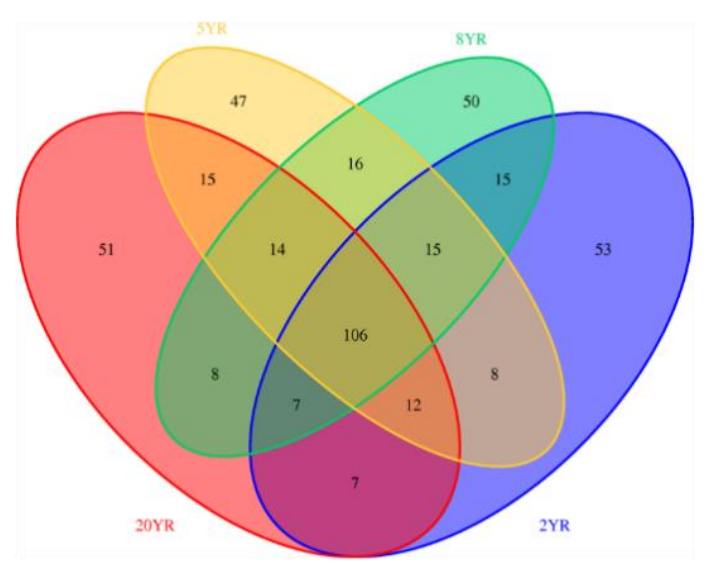

Figure 4. OTU Venn diagram of root samples in various age groups of stand

\section{Analysis of fungi community in roots of Machilus pauhoi in different age groups}

At the phylum level, there are 3 species with relative abundance more than $1 \%$. Ascomycota fungi accounts for the highest proportion $(60.98 \%)$, followed by Basidiomycota fungi (33.62\%), and Glomeromycota fungi accounts for the smallest proportion $(2.74 \%)$. According to the analysis of the proportion of all kinds of fungi, the fungi community in roots of Machilus pauhoi in different age groups presents a significant change (Fig. 5). From the interannual variation, in the roots of 5a Machilus pauhoi, the relative abundance of Basidiomycota is the highest while that of Ascomycota is the lowest. However, in the case of the roots of 8a Machilus pauhoi is the exact opposite. The relative abundance of Glomeromycota increases first and then decreases with the growth age. Compared with the 20a Machilus pauhoi, the fungi community in the roots of the 2a Machilus pauhoi has little change. On the whole, with the increase of growth age, the fungi community in the roots of Machilus pauhoi shows a certain degree of change and then returns to the similar structure in the young age (2a) at the phylum level.

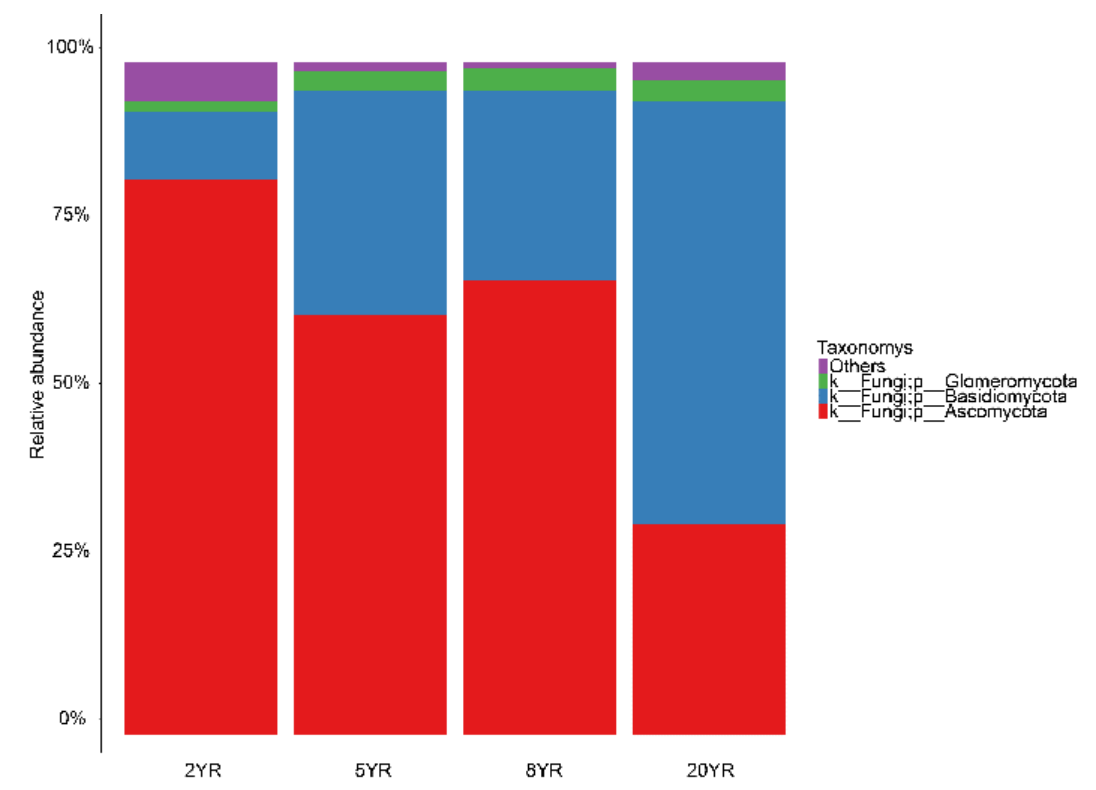

Figure 5. Composition of fungi community at a phylum level 
At the genus level, in each community, there were 8 genera with the relative abundance more than $1 \%$ in the roots of Machilus pauhoi (Fig. 6): Archaehorhizomyces, Chaetosphaeria, Clitocybula, Capronia, Muyocopron, Ochroconis, Parascutellinia and Phylchara. Among them, Clitocybula, Chaetosphaeria, Phylchara and Ochroconis were dominant species, accounting for $36.16 \%, 21.54 \%, 11.31 \%$ and $19.11 \%$, respectively. From the perspective of interannual variation, the composition of fungi communities in roots of Machilus pauhoi in different age groups also changes significantly (Fig. 4). The relative abundance of Clitocybula first increases and then decreases and further increases to the peak level at 20a. The relative abundance of Ochroconis decreases first, then increases and then decreases. The relative abundance of Chaetosphaeria increases with the extension of the growth age. The relative abundance of Parascutellinia does not change much with the increase of growth age. The relative abundance of Capronia is small, which appears to decrease first and then increase with the increase of growth age. Archaeorhizomyces has a relatively low abundance at young age, and reaches the maximum value after 20 years. It is worth noting that Phylchara only appears in the roots of 8a Machilus pauhoi, and ranks the largest proportion of each species.

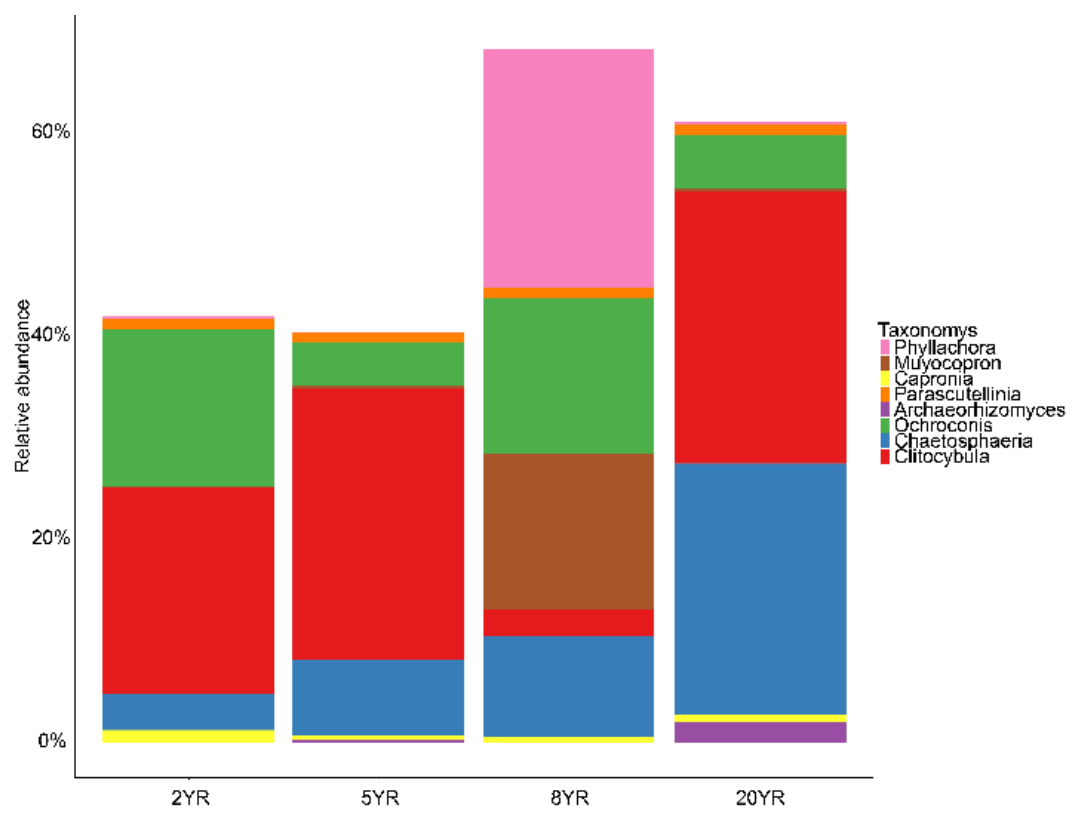

Figure 6. Composition of fungi community at a genus level

\section{The relative abundance distribution of fungi in roots of Machilus pauhoi in different age groups}

In terms of their abundance, the top 30 species are selected (all species are selected if there are less than 30 species). The relative abundance of fungi in the roots of Machilus pauhoi of different age groups are clustered based on their average abundance of different growth age at both the phylum and genus level, and the heatmap is obtained (Fig. 7). At phylum level, Blastocladiomycota and Annelida are most abundant in the roots of 20a Machilus pauhoi; Basidiomycota and Chytridiomycota are most abundant in the roots of 5a Machilus pauhoi; Arthropoda is most abundant in the roots of $2 \mathrm{a}$ Machilus pauhoi and Kickxellomycotina and Zoopagomycotina are most abundant in the 
roots of 20a Machilus pauhoi. The genera with high relatively abundances in each sample are also different: Chaetosphaeria, Capnobotryella, Phomopsis, Archaehorhizomyces, Henningsomyces and Heleiosa are most abundant in the roots of 20a Machilus pauhoi; Capronia, Phaeococcomyces and Pyxidiophora are most abundant in the roots of 2a Machilus pauhoi Camarophyllopsis, Cladochytrium and Boudiera are most abundant in the roots of 5a Machilus pauhoi and Conioscyphascus, Papulosa, Atractiella, Muyocopron, Phylchara and Galactomyces are most abundant in the roots of 8 a Machilus pauhoi, which indicates a difference in the abundance of fungi in the roots of Machilus pauhoi in different age groups. Due to the high similarity between the $2 \mathrm{a}$ and the 20 samples, they are grouped together. For the same reason, 5a and 8 a samples are clustered as one group.

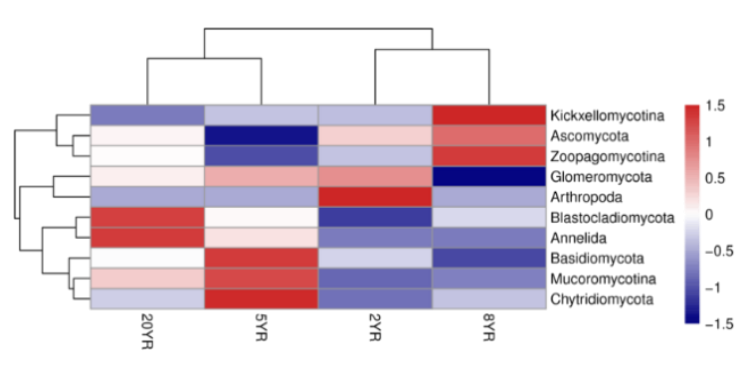

a

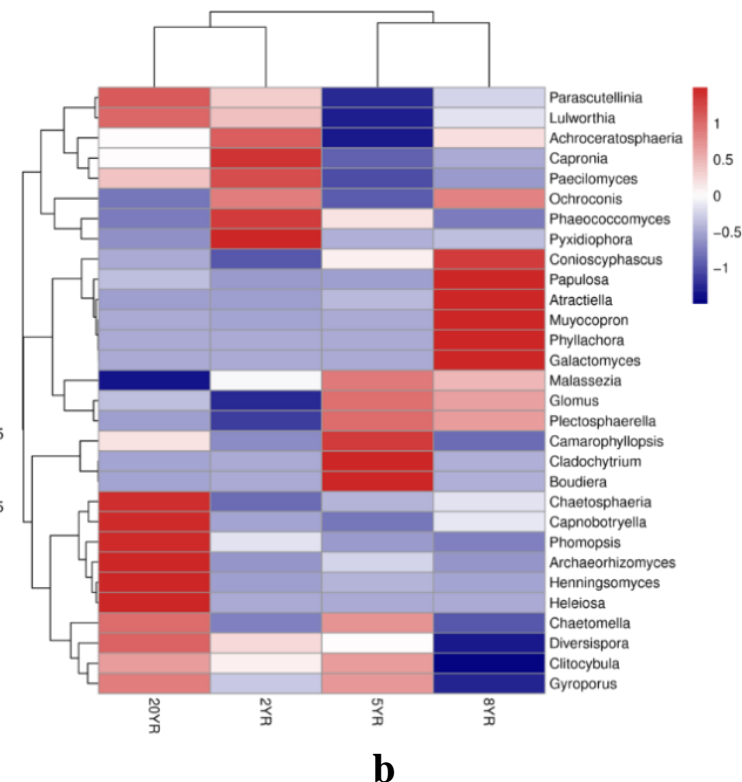

b

Figure 7. Abundance heatmap of species at different level of root samples in various age groups of stand (a: phylum; b: genus)

\section{Discussion}

High-throughput sequencing accurately reflects the composition and proportion of the fungi with different abundance in the roots of Machilus pauhoi, especially the species with low abundance, and objectively and comprehensively reveals the fungi structure in the roots in different age groups, making contributions to enriching plant endophytic resources and giving full play to high-throughput sequencing.

In this study, based on the Illumina Miseq sequencing platform, the diversity of fungi in the roots of Machilus pauhoi has been successfully detected, and a large amount of comprehensive and in-depth information on the fungi communities has been obtained. A total of 557,906 optimized sequences and 424 OTUs were obtained. A total of 10 fungi phyla and 32 genera were separated from the samples in different age groups. The rarefaction curves analyzed the sampling depth of root samples of different age groups. The number of OTUs in each sample presented the same or similar variation trend, that was, with the increase of sequencing depth, the increase of OTU number tended to slow down and eventually, reached basic saturation. 
The Machilus pauhoi in this study were in the same plantation but in different age groups, so the environmental difference was very small. The air humidity, climate, temperature, latitude and longitude, altitude, soil $\mathrm{pH}$ and concentrations of $\mathrm{N}, \mathrm{P}, \mathrm{K}$ and other soils in the same area were basically the same. During the experiment, a unified experimental method and data analysis method were employed. Therefore, the growth age became the dominant factor in the diversity of fungi in the roots of Machilus pauhoi.

A total of 424 fungi OTUs were obtained from Machilus pauhoi in 4 different age groups. According to the Venn diagram (Fig. 4), in the second and eighth year, the number of OTU is large, but it is small in fifth and twentieth year. With the increase of growth age, the fungi abundance and diversity index decreases first and then increases, reaching minimum value in the eighth year. In the analysis of community structure, with the increase of the age, the community structure of endophytic fungi in the roots of Machilus pauhoi changes dramatically. In the cluster analysis of relative abundance in different age groups, the fungi in $2 \mathrm{a}$ and $20 \mathrm{a}$ samples are clustered as one group and fungi in 5a and 8a samples are grouped together, indicating that the composition of endophytic fungi in second and twentieth year is more similar but is different from that in the fifth and eighth year. The results indicate that, with the increase of age, the fungi community in the roots of Machilus pauhoi changes to a certain degree and then goes back to the young age.

Through the above results, it can be clearly seen that there are a large number of endophytic fungi colonization with great diversity in the roots of Machilus pauhoi in the plantation. However, with the growth and development of Machilus pauhoi, endophytic fungi colonized in its roots have undergone certain changes, which might be related to the regulation of plants themselves in the process of adapting to the environment. When the plant was initially planted in the plantation field, there were lots of endophytic fungi in the roots. However, as the growth and development of plant and adaption to the environment, the number of competitive relationships among endophytic fungi colonized in the roots decreases. Then, after the plants slowly adapt to the surrounding environment, some fungi have established stable parasitic relationships with plants. Therefore, the number of fungi colonized in the roots of the plants increases.

It is worth noting that the characteristic genus, Phylchara, appears in the roots of $8 \mathrm{a}$ Machilus pauhoi, and its relative abundance is the highest among all species. This might be related to the decline in quality and productivity in forest land soil. Ascomycotina, Ascomycetes, Phyllachorales, and Phyllachoraceae are a class of obligate parasitic vegetative fungi (Mccoy et al., 2018; Denman et al., 1999). The Phyllachora fungi are widely distributed in plants in tropical and subtropical regions. Phyllachora graminis is a main kind of plant disease for precious tropical native species in Hainan Province, such as Dalbergia odorifera, Pterocarpus macrocarpus, and Pterocarpus santalinus (Liu et al., 2016). Combined with the symptoms of Phyllachora graminis (Levente et al., 2018; Reddell et al., 1999; Egham et al., 1992), it can speculate that the scabs formed on Machilus pauhoi might be related to these species, but further experimental verification is needed. Moreover, the reduction of fungal community diversity in eighth year might be related to the dominant position of phytopathogenic fungi. 


\section{Conclusions}

This study, for the first time, used high-throughput sequencing method to study the fungi community structure in the roots of Machilus pauhoi, a secondary protected plant, in the experimental forest in Yangshan County, Qingyuan City, Guangdong Province. The results show that endophytic fungi in the roots have a great diversity and great research value. The dominant species are Ascomycota and Basidiomycota at phylum level and Clitocybula. Ochroconis and Chaetosphaeria at genus level. With the increase of the age, the fungi abundance and diversity index decreases first and then increases. Phylchara, might be related to scabs formed on Machilus pauhoi, appears in the roots of 8a Machilus pauhoi. These conclusions can provide a theoretical basis for the protection of the community of Machilus pauhoi. Personally, the experiment only focused on the change of fungal community structure, ignoring the effect of other factors such as bacteria. Future researches should carry out multiple factors analysis and comparative experiments to explore the regulatory relationship between other factors such as microorganisms, insects and human activities destruction and the structure and function of the fungal.

Acknowledgements. This work was financially supported by China West Normal University Doctoral Startup Research Project (412666).

\section{REFERENCES}

[1] Azevedo, J. L., Maccheroni, J. W., Pereira, J. O., Araujo, W. L. (2000): Endophytic microorganisms: a review on insect control and recent advances on tropical plants. Electronic Journal of Biotechnology 3(1): 15-16.

[2] Caron, D. A., Countway, P. D., Savai, P. et al. (2009): Defining DNA-based operational taxonomic units for microbial-eukaryote ecology. - Applied and Environment Microbiology 75(18): 5797-5808.

[3] Chapin, F. S., Walker, B. H., Hobbs, R. J. et al. (1997): Biotic Control over the Functioning of Ecosystems. - Science 277(5325): 500-504.

[4] Denman, S., Crous, P. W., Wingfield, M. J. (1999): A taxonomic reassessment of Phyllachora proteae, a leaf pathogen of Proteaceae. - Mycologia 91(3): 510-516.

[5] Egham, S. (1992): Imi Descriptions of Fungi and Bacteria. - Mycopathologia 120: 45-46.

[6] Guo, L. D., Hyde, K. D., Liew, E. C. Y. (2000): Identification of endophytic fungi from Livistona chinensis based on morphology and rDNA sequences. - New Phytologist 147(3): 617-630.

[7] Guo, X. F., Li, H. S., Chen, H. Y. (2017): The effects of biochar and intercropping on the $\mathrm{Cd}, \mathrm{Cr}$ and $\mathrm{Zn}$ speciation in soils and plant uptake by Machilus pauhoi. - Bulletin of Environmental Contamination and Toxicology 98(4): 574-581.

[8] Iranshahi, D. R., Sepehri, M., Khoshgoftarmanesh, A. H. et al. (2016): Inoculation effects of endophytic fungus (Piriformospora indica) on antioxidant enzyme activity and wheat tolerance under phosphorus deficiency in hydroponic system. - Journal of Science \& Technology of Greenhouse Culture 6(4): 75-86.

[9] Jeanbille, M., Buée, E. M., Bach, C. et al. (2016): Soil Parameters Drive the Structure, Diversity and Metabolic Potentials of the Bacterial Communities Across Temperate Beech Forest Soil Sequences. - Microbial Ecology 71(2): 482-493.

[10] Kaushik, N., Kumar, V. (2013): Endophytic Fungi for Stress Tolerance. - In: Tuteja, N., Gill, S. S. (eds.) Climate Change and Plant Abiotic Stress Tolerance. - Wiley-VCH, New York, pp. 1041-1052. 
[11] Kumar, M., Qadri, M., Sharma, P. R. et al. (2013): Tubulin inhibitors from an endophytic fungus isolated from Cedrusdeodara. - Journal of Natural Products 76: 194-199.

[12] Kuramae, E., Gamper, H., Van, V. J. et al. (2011): Soil and plant factors driving the community of soil-borne microorganisms across chronosequences of secondary succession of chalk grasslands with a neutral pH. - Fems Microbiology Ecology 77(2): 285-294.

[13] Knezevic, S. Z., Streibig, J. C., Ritz, C. (2007): Utilizing R software package for doseresponse studies: the concept and data analysis. - Weed Technology 21: 840-848.

[14] Levente, K., Gábor, M. K., Károly, B. et al. (2018): Deciphering the biology of Cryptophyllachora eurasiatica gen. et sp. nov., an often cryptic pathogen of an allergenic weed, Ambrosia artemisiifolia. - Scientific Reports 8(1): 10806.

[15] Liu, Q. L., Zhou, G. Y., Li, H. et al. (2016): Rapid molecular diagnosis of Phyllachora dalbergiicola in Dalbergia odorifera. - Acta Phytopathologica Sinica 46(1): 135-139 (in Chinese).

[16] Mccoy, A. G., Romberg, M. K., Zaworski, E. et al. (2018): First report of tar spot on corn (Zea mays) caused by Phyllachora maydis in Florida, Iowa, Michigan and Wisconsin. Plant Disease 102(9): 1851.

[17] Mukerji, K. G. (1996): Concepts in Mycorrhizal Research. - Springer, New Delhi.

[18] Petrini, O. (1991): Fungal Endophytes of Tree Leaves. - In: Andrews, J. H., Hirano, S. S. (eds.) Microbial Ecology of Leaves. Springer, New York, pp. 179-197.

[19] Rappaport, D., Montagnini, F. (2014): Tree species growth under a rubber (Hevea brasiliensis) plantation: native restoration via enrichment planting in southern Bahia, Brazil. - New Forests 45(5): 715-732.

[20] Reddell, C. A., Reddell, P., Hyde, K. D. (1999): A revision of Phyllachora (Ascomycotina) on hosts in the angiosperm family Asclepiadaceae, including $P$. gloriana sp. nov. on Tylophora benthamii from Australia. - Fungal Diversity 3: 123-138.

[21] Rodrigue, R. J., Redman, R. S., Henson, J.M. (2004): The role of fungal symbioses in the adaptation of plants to high stress environments. - Mitigation and Adaptation Strategies for Global Change 9(3): 261-272.

[22] Rout, M. E. (2014): The plant microbiome. - Adv Bot Res 69: 279-309.

[23] Schmit, J. P., Shearer, C. A. (2004): Geographic and host distribution of lignicolous mangrove microfungi. - Botanica Marina 47: 496-500.

[24] Smith, K. P., Goodman, R. M. (1999): Host variation for interactions with beneficial plant-associated microbes. - Annual Review of Phytopathology 37: 473-491.

[25] Stone, J. K., Bacon, C. W., James, F. J. (2000): An overview of endophytic microbes: Endophytism defined. - Microbial Endophytes 9: 267-274.

[26] Thiem, D., Piernik, A., Hrynkiewicz, K. (2018): Ectomycorrhizal and endophytic fungi associated with Alnus glutinosa growing in a saline area of central Poland. - Symbiosis 75(1): 17-28.

[27] Vandenkoornhuyse, P., Quaiser, A., Duhamel, M., Le Van, A., Dufresne, A. (2015): The importance of the microbiome of the plant holobiont. - New Phytologist 206(4): 11961206.

[28] Wei, S. D., Chen, R. Y., Liao, M. M. et al. (2011): Antioxidant condensed tannins from Machilus pauhoi leaves. - Journal of Medicinal Plants Research 5(5): 796-804.

[29] Zhao, X. M., Wang, Z. Q., Shu, S. H. et al. (2013): Ethanol and methanol can improve huperzineaproduction from endophytic Colletotrichumgloeosporides ES026. - PLoS One 8(4): e61777.

[30] Zhong, Q. L., Cheng, D. L., Hu, S. Z., He, L. Z., Tang, C. C., Wen, Y. X., Qiu, J. F., Li, X. H. (2009): Chlorophyll content and net photosynthetic rate of Machilus pauhoi and $M$. leptophylla. Chin. - J Appl Ecol 20(2): 271-276 (in Chinese). 